\title{
ANATOMIA Y DESARROLLO DE FLORES, FRUTOS Y SEMILLAS \\ DE BOLDO (PEUMUS BOLDUS MOL.) (*)
}

Claudia Botti G.

\section{RESUMEN}

Se describe la anatomía y desarrollo de flores, frutos y semillas de boldo (Peumus boldus Mol.) con el fin de proporcionar nuevos antecedentes que contribuyan a comprender los mecanismos de latencia que presentan las semillas de esta especie.

El material vegetal se recolectó entre fines de invierno y mediados de verano, en la Región Metropolitana. Las flores y frutos se infiltraron en JB-4 (Polyscience, Inc.) y se cortaron con ultramicrótomo (2-4 $\mu \mathrm{m}$ espesor); las semillas se incluyeron en parafina (Histosec) y se cortaron con micrótomo rotatorio (8$10 \mu \mathrm{m})$.

El desarrollo del saco embrionario se inició en agosto. El zigoto comenzó a dividirse a fines de septiembre, y a principios de diciembre el embrión inició la organización de los ápices de crecimiento, y desarrollo de los cotiledones. Durante el mes de febrero cl embrión cesó su crecimiento y el fruto completó su maduración, presentando en su interior un embrión incompletamente desarrollado.

La semilla, al madurar el fruto, presentaba remanentes de la nucela, diferenciada en perisperma, rodeando al endosperma y embrión.

Palabras claves: Peumus boldus Mol.; anatomía; semillas.

\section{ABSTRACT}

The anatomy and development of flowers, fruits and seeds of Peumus boldus Mol. is described to provide more background for a better understanding of the dormancy mechanisms occurring in the seeds of this species.

The plant material was collected between late winter and mid-summer in the Metropolitan Region. Flowers and fruits were infiltrated in JB-4 (Polyscience, Inc.) and were sectioned with an ultranicrotome $(2-4 \mu \mathrm{m}$ width); the seeds were embedded in paraffin (Histosec) and were sectioned with a rotatory microtome (8$10 \mu \mathrm{m})$.

The development of the embryo sac started in August. The zygote started to divide in late September and, in early December, the embryo began the organization of shoot and root apices and the development of cotyledons. During February, the embryo stopped growing and the fruit completed its maduration, showing an incompletely developed embryo in its interior.

As the fruit matured, the seed showed rests of mucellus, differentiated as perisperm, surrounding the endosperm and embryo.

(*) Financiado por el Departamento de Investigación y Bibliotecas, Universidad de Chile. Proyecto A-107.8422.

$\left(^{* *}\right)$ Ingeniero agrónomo, M. Sc., Profesora, Directora del Departamento de Producción Agrícola, Facultad de Ciencias Agrarias y Forestales, Universidad de Chile. Casilla 1004, Santiago, Chile.

${ }^{(* * *}$ Ingeniero Forestal. Profesor del Departamento de Silvicultura, Facultad de Ciencias Agrarias y Forestales, Universidad de Chile. Casilla 9206, Santiago, Chile. 


\section{INTRODUCCION}

El boldo (Peumus boldus Mol.), especie endémica de Chile perteneciente a la familia Monimiaceae, crece desde la Provincia de Limarí (IV Región) hasta la Provincia de Osorno (X Región) (Rodríguez et al. 1983). Debido a su adaptación a condiciones de sequía, es más abundante en las provincias centrales que en las del sur (Donoso, 1974).

Es un árbol o arbusto dioico, con inflorescencias en racimos cortos. Sus flores, de 5 a $10 \mathrm{~mm}$ de diámetro, presentan un perigonio verdoso, cubierto de pelos estrellados y escamas petaloídeas blanco-amarillentas insertas en su garganta. Las flores masculinas, de mayor tamaño, presentan más de 40 estambres. Las femeninas poseen un gineceo súpero, con 2 a 9 ovarios libres y uniloculares, con un solo óvulo cada uno; estigma arqueado y gelatinoso. En las flores femeninas los estambres están representados por escamas nectaríferas. Sus frutos son drupas más o menos ovoides, carnosas, de 5 a $7 \mathrm{~mm}$ de longitud (Navas, 1976).

Su hojas se usan en infusión como digestivo; en afecciones hepáticas se le considera un excelente colagogo y colerético. En 1960, Valenzuela y Rebolledo (citados por Navas, 1976) determinaron que las hojas, además de la boldina, contenían otros tres alcaloides, un glucósido, $2 \%$ de aceites esenciales, taninos, ácido cítrico, gomas y azúcares. Según Rodríguez et al., (1983) los aceites esenciales son eugenol y terpineol.

Kannegiesser (1987) demostró que la boldina se encuentra en todo el árbol, conteniendo la corteza el mayor porcentaje $(3,7 \%)$ y las hojas el menor $(0,03 \%)$. Además, informa que entre 1983 y 1986 se ha exportado un promedio anual de 786 ton de hojas y 6 ton de corteza, principalmente a Europa, Argentina y Brasil.

Aunque el boldo rebrota fácilmente, ha sido sometido desde hace muchos años a una fuerte explotación, sin que se repongan los ejemplares que mueren por agotamiento del tocón, o porque los árboles son destroncados o por la destrucción del ambiente apropiado para su reproducción por semillas. De hecho, en la zona central es muy raro encontrar plántulas en los lugares donde aún existen ejemplares de boldo.

Por otra parte, su propagación en vivero es difícil, ya que sus semillas sembradas en otoño o invierno, no germinan hasta el invierno del año siguiente. Generalmente el porcentaje de germinación es bajo, produciéndose una nueva germinación durante el invierno del segundo año.

Algunos investigadores han tratado de encontrar tratamientos pregerminativos, o la época de siembra apropiada, para obtener germinación en un corto período. Los resultados en algunos casos han sido nulos o no han superado al testigo (Homann, 1968; Donoso y Cabello, 1978). En otros se ha obtenido desde $0 \%$ hasta $89 \%$ de germinación, en pocos meses, mediante colecta temprana y siembra inmediata (Mancinelli et al., 1982; Muñoz, 1986); sin embargo, los resultados obtenidos en años consecutivos han sido muy dispares, incluso en una misma temporada, entre cosechas y siembras separadas por una semana.

En 1986, Muñoz, demostró que el ácido giberélico promovía significativamente la germinación de semillas de boldo almacenadas por un corto período. También obtuvo germinación, aunque en bajo porcentaje, mediante remojo de las semillas en peróxido de hidrógeno. Además, mediante el cultivo de semillas y embriones "in vitro", estableció que el 
endocarpio, la testa y/o el perisperma, eran limitantes para la germinación, ya que el cultivo de embriones entregó un $100 \%$ de germinación, iniciándose el proceso luego de 10 a 15 días.

En base a los resultados obtenidos por Muñoz (1986), se decidió a estudiar la anatomía y desarrollo de la semilla del boldo y así contribuir con nuevos antecedentes al conocimiento de la especie, particularmente en lo que a reproducción sexual se refiere.

\section{MATERIAL Y METODO}

Se recolectaron yemas florales, flores y frutos de boldo con distintos grados de desarrollo, cada 15 días entre agosto y febrero. Todo el material provino del fundo "Tantehue", ubicado a $30 \mathrm{Km}$. al suroeste de Melipilla, Región Metropolitana.

El material vegetal se fijó en FAA (formalina, ácido acético glacial y etanol, 5:5:90 v/ v) por un tiempo mínimo de 24 horas, y se deshidrató gradualmente en una serie de alcohol etílico $(70 ; 80 ; 95$ y $100 \%)$.

Las semillas fueron incluidas en parafina sólida (Histosec), previo traspaso gradual a xilol, y cortadas a 8-10 $\mu \mathrm{m}$ de espesor en un micrótomo rotatorio. Las secciones fueron teñidas con ácido tánico-cloruro de fierro (Foster, 1934) y safranina al 1\% (solución alcohólica), luego con verde rápido al $0,2 \%$ (solución alcohólica) y se montaron con Bálsamo de Canadá.

Las yemas, flores y frutos inmaduros fueron infiltrados con plástico JB-4 (Polyscience Inc.) previa fijación y deshidratación. Los bloques de plástico, con el tejido incluido, se cortaron con cuchillos de vidrio a 2-4 $\mu \mathrm{m}$ de grosor en un ultramicrótomo. Los cortes se tiñeron con Reactivo de Schiff y Azul de Toluidina al 0,5\% en solución acuosa y se montaron en Bálsamo de Canadá (Botti y Vasil, 1984).

\section{RESULTADOS Y DISCUSION}

Los sépalos y pétalos de la flor de boldo están formados por una epidermis uniseriada, de células grandes y globosas. La epidermis abaxial (exterior en la yema) de los sépalos presenta numerosos tricomas ramificados, como menciona Navas (1976), de paredes celulares primarias gruesas. La epidermis adaxial presenta pocos tricomas. El mesófilo de ambas estructuras florales es esponjoso, con grandes espacios intercelulares, glándulas y pequeños haces vasculares en la sección ventral. El mesófilo de los sépalos es de mayor grosor (4-8 corridas de células). El de los pétalos es de sólo 3-4 corridas de células.

El estilo y ovario presentan una epidermis monoestratificada de células rectangulares elongadas en sentido radial, de núcleos muy prominentes, recubiertas por una cutícula muy delgada y con paredes celulares también delgadas. Numerosos tricomas tipo escamas multicelulares y colectores de pared celular sumamente gruesa, se encuentran dispersos a lo largo de toda la epidermis de los carpelos. El mesófilo del ovario está formado por varias corridas (14) de células parenquimáticas, pequeñas, de paredes delgadas y tejido vascular central que lo recorre longitudinalmente. Algunas glándulas equizógenas se encuentran distribuidas en este tejido, especialmente en la zona más externa, cercana a la epidermis. La epidermis interna del ovario es monoestratificada en algunos sectores, pero en la mayor parte se ha 
dividido periclinalmente para formar hasta 3 corridas de células, que más tarde se van a seguir incrementando para formar el endocarpio duro del fruto, junto con la porción interna del mesófilo.

El óvulo es anátropo y bitégmico (Figura 1). El tegumento externo se desarrolla claramente en el lado opuesto al funículo que rodea al óvulo, y consta de 3 corridas de células con las mismas características que las de mesófilo y epidermis interna del ovario. No se observan acumulaciones de sustancias fenólicas o taninos. El funículo consta de 20-24 corridas de células en su parte superior más ancha para adelgazarse a 4-5 corridas al conectarse con el tegumento externo en su parte basal. Lo recorre un haz vascular. El tegumento interno está formado por 3-4 corridas de células en su mayor extensión, engrosándose a 7-8 corridas en la base del óvulo y a 5-7 corridas en la zona de la micropila. La nucela, de 25-30 corridas en su parte más ancha, inicia el desarrollo del saco embrionario en el mes de agosto, formando la célula huevo, dos sinérgidas, una célula central y 3 antípodas (Figura 2). Después de la fertilización el saco embrionario ha crecido y se encuentra ocupando gran parte de lo que era la nucela; sin embargo permanecen 6-8 corridas de células nucelares rodeándolo, tejido que posteriormente permanece rodeando al endosperma donde recibe el nombre de perisperma.

\section{FIGURA 1}

Ovario de Flor de Boldo con óvulo Anátropo y saco embrionario formado

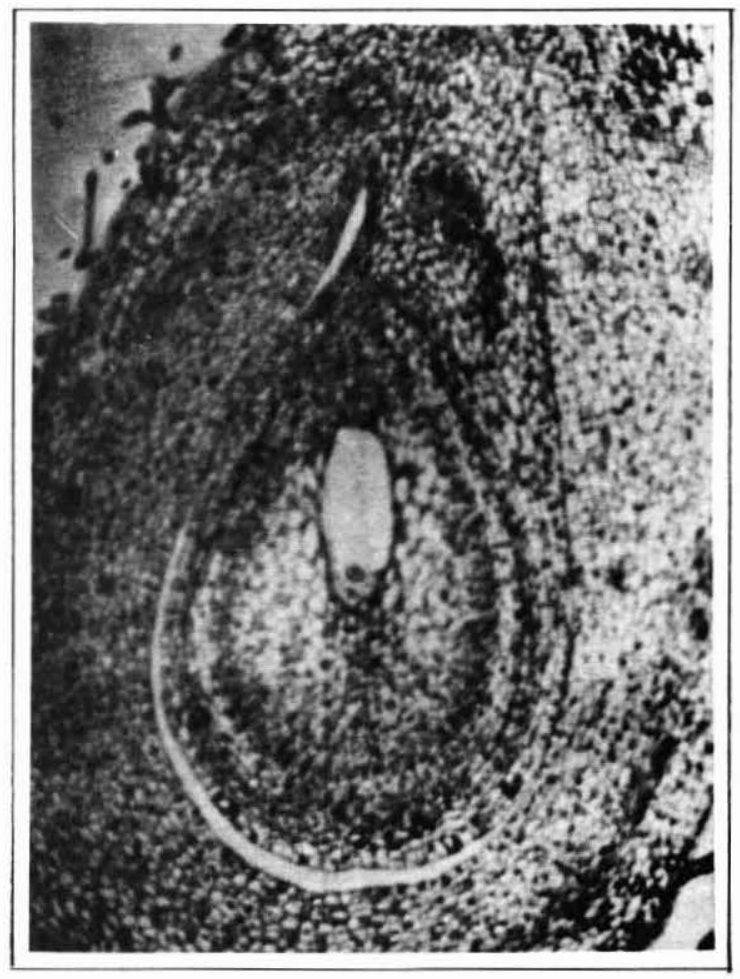




\section{FIGURA 2}

Saco embrionario, donde se observa la célula huevo (ch), el núcleo secundario (ns) y parte de las antípodas (a), rodeado por la nucela (n) (las sinérgidas no aparecen por estar en otro plano del saco embrionario)

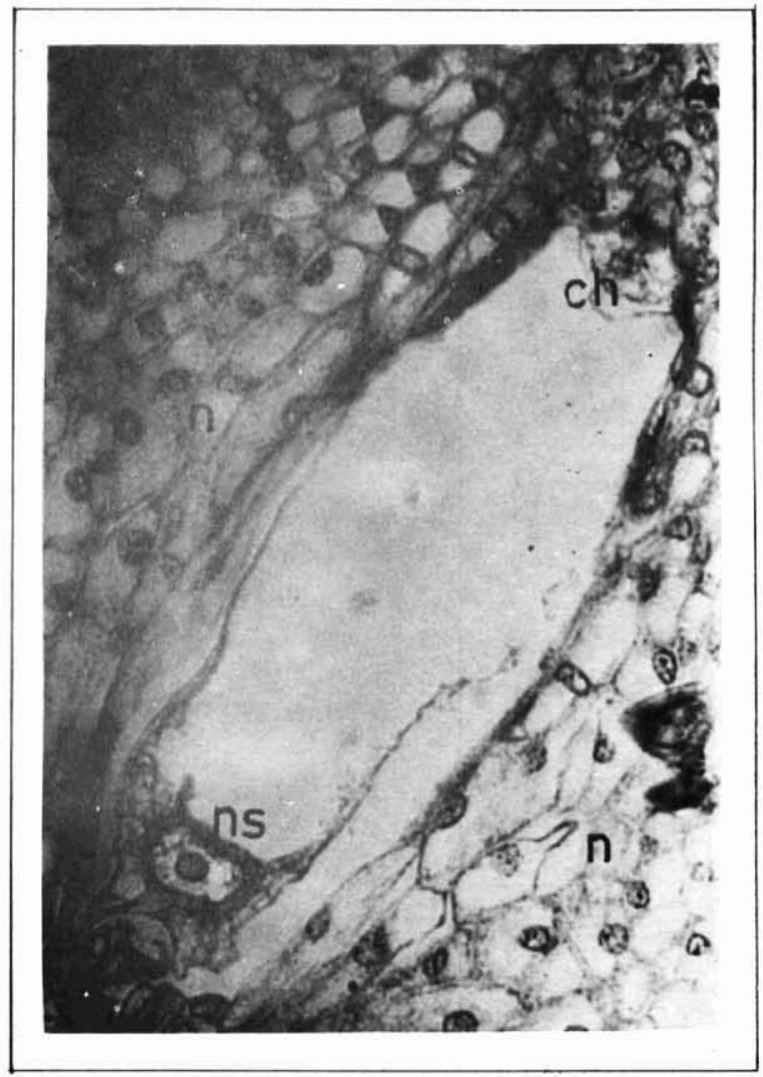

El zigoto inicia sus divisiones un mes después de la formación del saco embrionario (fines de septiembre) (Figuras 3 y 4), cuando el endosperma aún es líquido y de núcleos libres. La porción interna del mesófilo del ovario (desde los haces vasculares hacia el interior) junto con la epidermis interna del mismo inician, en este momento, una esclerosis de las células que dará origen al endocarpio extremadamente duro del fruto del boldo (Figura 5). No se observan cambios notables en los tegumentos, salvo un aumento en el tamaño de las células, especialmente del tegumento interno. El mesófilo externo (mesocarpio) muestra un aumento notorio en el número de glándulas. 


\section{FIGURA 3}

Zigoto en división (fines de septiembre)

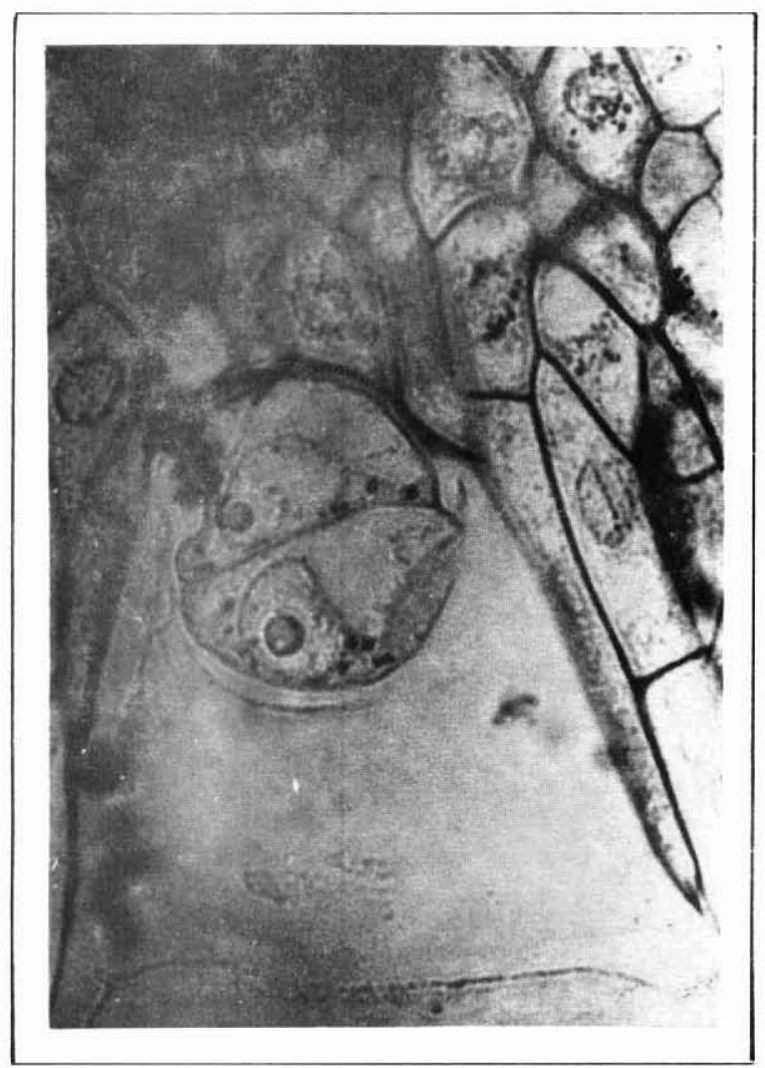


CLAUDIA BOTTI G. - ANGEL CABELLO L.

\section{FIGURA 4}

Embrión en estado de cuadrante, con suspensor

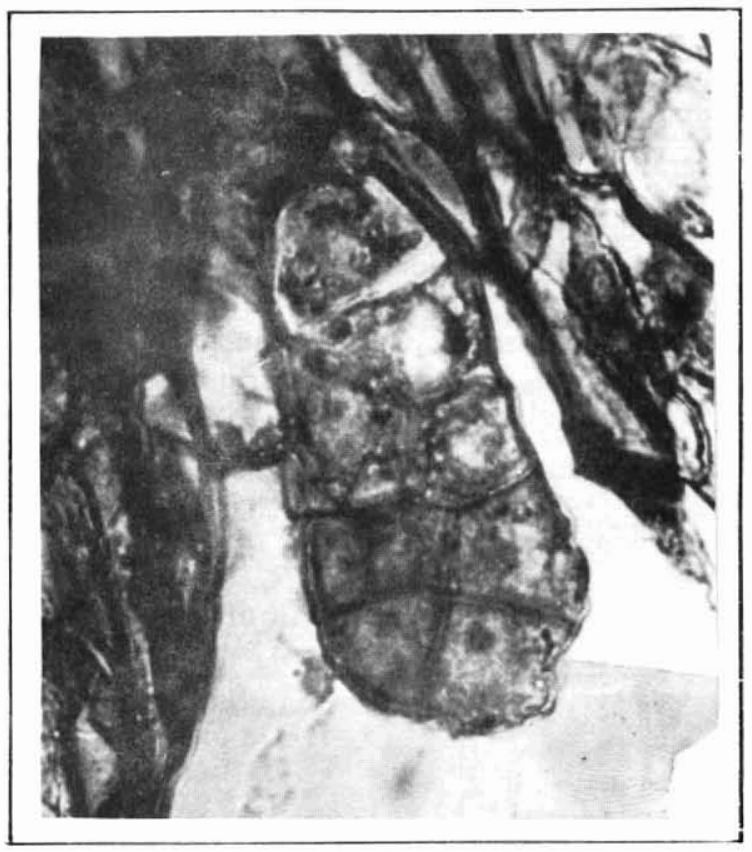

FIGURA 5

Endocarpio iniciando Esclerosis al 30 de septiembre

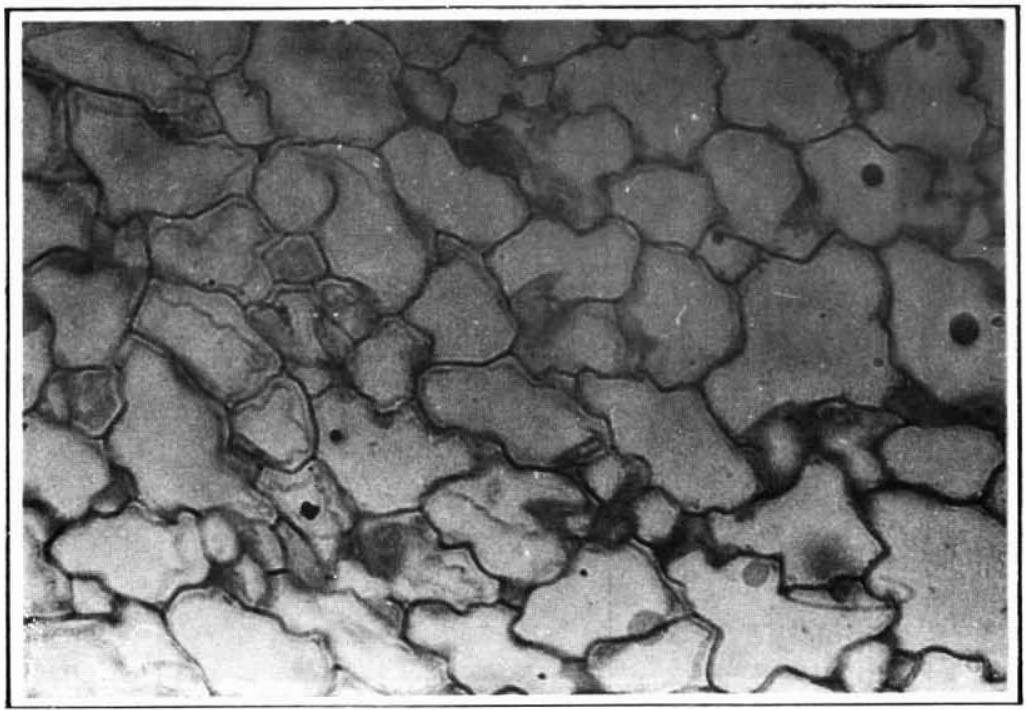


Cuando el embrión llega al cstado globular, (Figura 6) el endosperma continúa líquido, de núcleos libres, pero se observan los primeros indicios de organización de pared alrededor de algunos. Las células del tegumento externo inician engrosamientos de pared de tipo reticulado, especialmente en la zona cercana al embrión en desarrollo.

Después de aproximadamente 2 meses desde la primera división del zigoto (principios de diciembre), el embrión mucstra los dos cotiledones diferenciados y clongados y un inicio de organización de ápice radicular y de brote. El endosperma ya se ha hecho celular y ha comenzado a acumular sustancias de reservas. Asimismo la nucela permanece rodeando al endosperma, ahora con el nombre de perisperma y también con fuerte acumulación de sustancias ergásticas. Estas no fueron identificadas químicamente, pero se presentaban diferentes en forma, tamaño y color a las del endosperma (Figura 7). El endocarpio, formado ahora por braquiesclereidas se presenta sumamente lignificado y duro (Figura 8). Todo el proceso de maduración de las paredes del fruto y desarrollo del embrión continua hasta febrero, fecha en que el embrión ha llegado a su máximo crecimiento dentro

\section{FIGURA 6}

Embrión globular (e), rodeado por restos de nucela (n) y tegumentos (t).

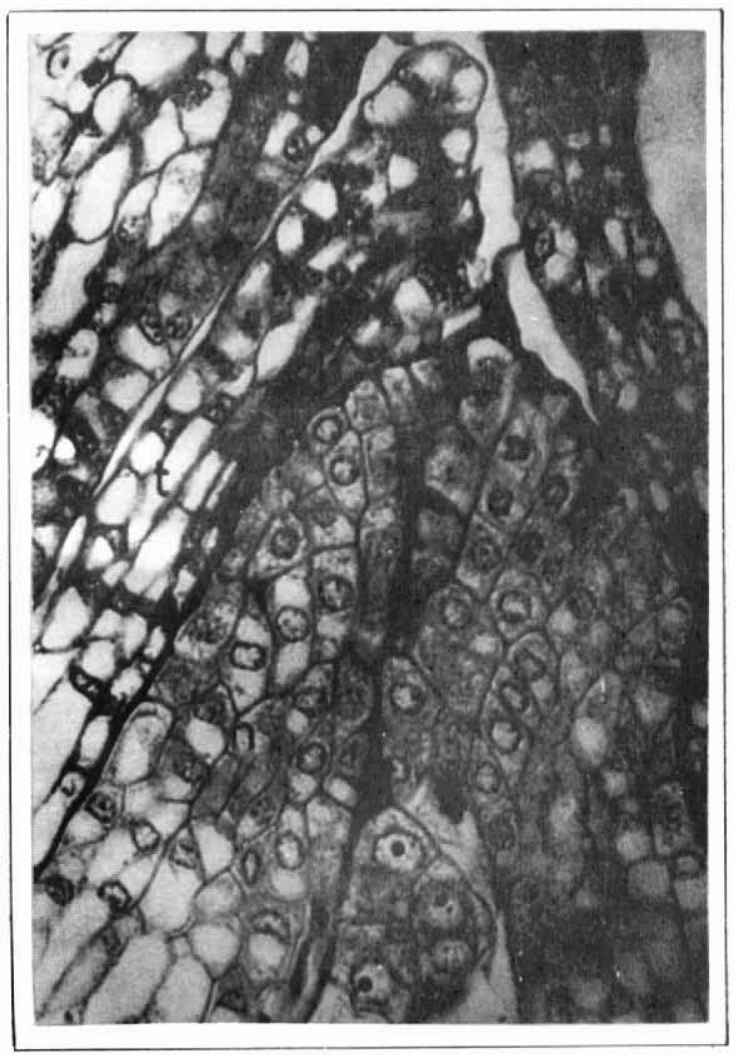


de la semilla, mostrando los dos cotiledones apoyados en un ángulo abierto sobre el endosperma con el ápice radicular hacia el exterior (Figura 9). El perisperma, que presenta aproximadamente 10 corridas de células en toda su extensión, se adelgaza y aplasta frente a la radícula. Los tegumentos también se adelgazan, especialmente el tegumento interno, permaneciendo como cubierta seminal el tegumento externo formado por 3-4 corridas de células con engrosamiento reticulado en su pared (Figura 10).

De acuerdo con los grupos definidos por Hartmann y Kester (1983), el desarrollo máximo a que llega el embrión del boldo, cuando el fruto cae del árbol, corresponde al de un embrión incompletamente desarrollado, especialmente en lo que respecta a los cotiledones que son muy pequeños. La mayor parte del volumen de la semilla está ocupado por el endosperma y perisperma. Sin embargo, esto no sería determinante en la mala germinación del boldo, ya que Muñoz (1986) logró un 100\% de germinación al cultivar embriones desnudos "in vitro".

El hecho que el endocarpio esté completamente diferenciado y endurecido a mediados de noviembre, 3 meses antes de la caída de los frutos, así como la presencia del perisperma y la cubierta seminal, podrían explicar los bajos porcentajes de germinación que se han logrado (Homann, 1968; Donoso y Cabello, 1978), incluso adelantando la época de cosecha y siembra a diciembre (Mancinelli et al.,, 1982), ya que en la germinación de esta especie habría, de acuerdo con MUÑOZ (1986), una combinación de barreras mecánica y fisiológica que impiden o retardan este proceso.

\section{FIGURA 7}

Sustancias ergásticas en células de Perisperma (p)

y Endosperma (en).

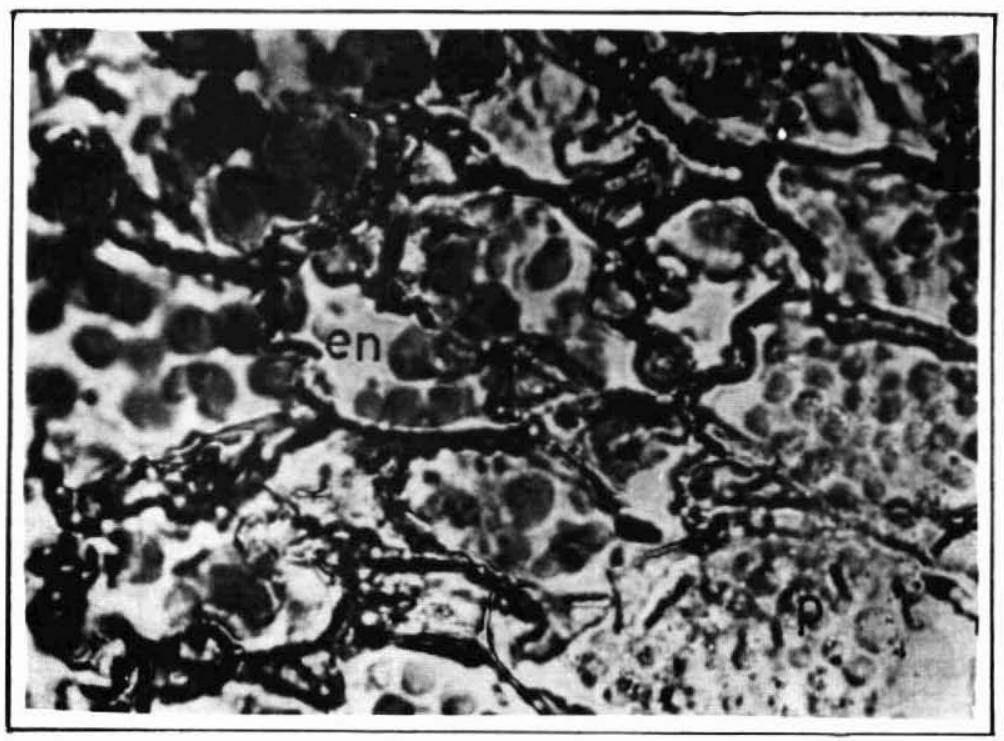




\section{FIGURA 8}

Endocarpio al 15 de noviembre

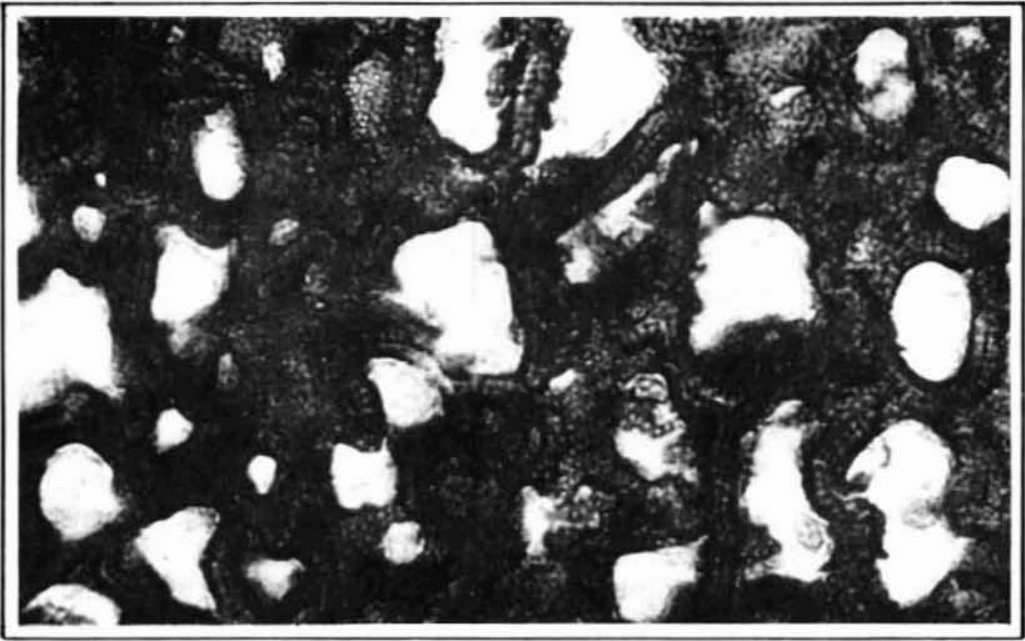

FIGURA 9

Embrión de semilla madura. Se observa la radícula (r), cotiledones (c), perisperma (p) y endosperma (en).

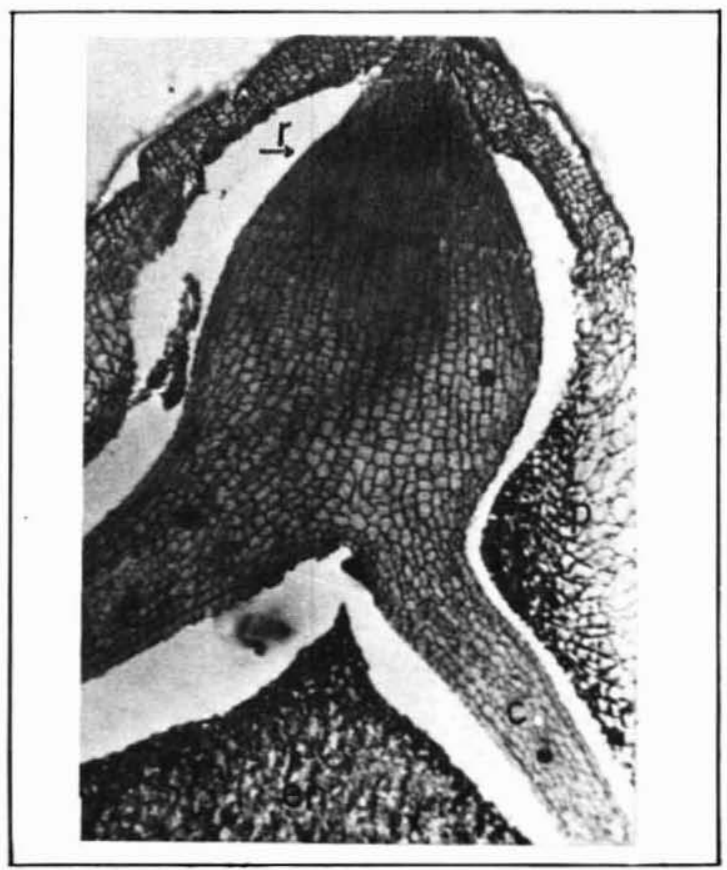




\section{FIGURA 10}

Capas de la semilla madura: testa(te), perisperma (p), endosperma (en) y extremo de un cotiledón (c).

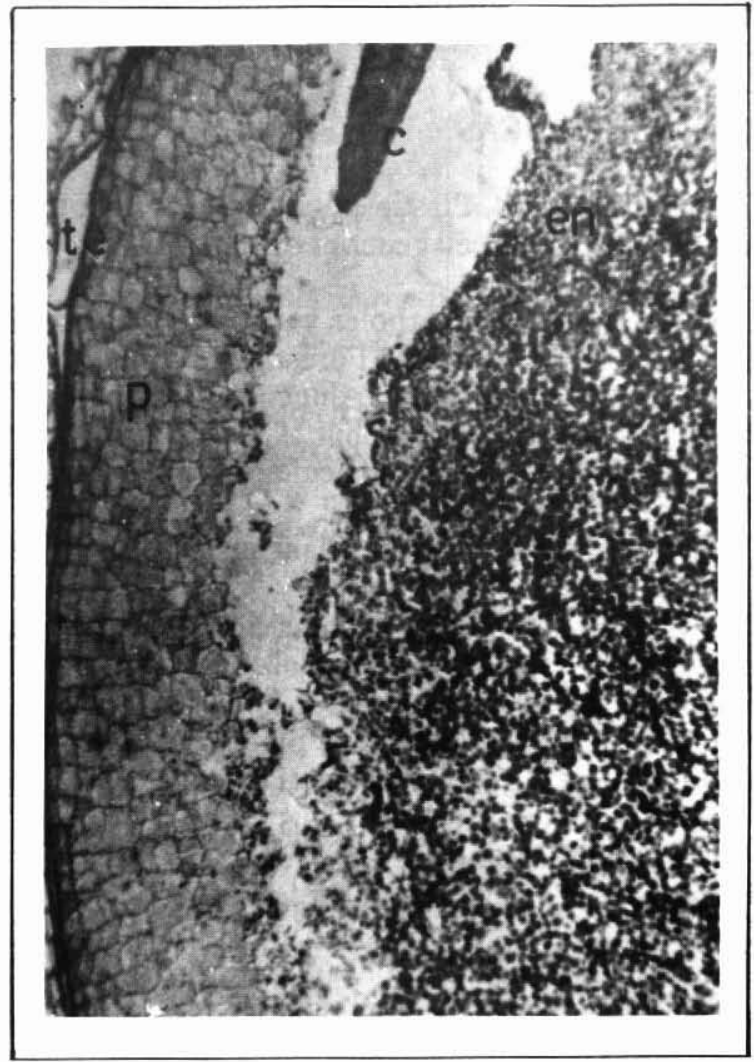

\section{CONCLUSIONES}

El óvulo de la semilla del boldo, es anátropo y bitégmico.

La nucela inicia el desarrollo del saco embrionario en cl mes de agosto.

El zigoto inicia sus divisiones a fines de septiembre; al mismo tiempo, las células de la porción interna del mesófilo comienzan una esclerosis lo que dará origen al endocarpio óseo.

A comienzos de diciembre el embrión presenta dos cotiledones diferenciados y un inicio de organización en el ápice radicular y en el brote; el endosperma ha comenzado a acumular sustancias de reserva, y la nucela se ha transformadoen el perisperma rodeando al embrión y al endosperma. El endocarpio, formado por braquiesclereidas, se presenta sumamente lignificado y duro.

- $\quad$ El proceso de maduración del fruto y la semilla continúa hasta febrero.

- La mayor parte del volumen de la semilla madura corresponde al endosperma y 
perisperma, encontrándose el embrión incompletamente desarrollado, especialmente en lo que respecta a los cotiledones.

- El endocarpio constituye, probablemente, una barrera física que retrasa el proceso de germinación y el perisperma y testa podrían corresponder a barreras de tipo fisiológico en este proceso.

\section{REFERENCIAS BIBLIOGRAFICAS}

1. BOTTI, C. y VASIL, I. K. 1984. Plastic embedding for light microscopy. En: Vasil, I. K. (ed). Cell culture and somatic cell genetics of plants. Orlando, Florida. Academic Press. v.1. pp. $684-688$.

2. DONOSO, C. 1974. Dendrología. Arboles y arbustos chilenos. Santiago, Chile. Universidad de Chile, Facultad de Ciencias Forestales. Manual № 2. 142 p.

3. DONOSO, C. y CABELLO, A. 1978 Antecedentes fenológicos y de germinación de especies leñosas chilenas. Santiago, Chile. Ciencias Forestales 1 (2): 31-41.

4. FOSTER, A. S. 1934. The use of tannic acid and iron chloride for staining cell walls in meristematic tissue. Stain Tech. 9:91-92.

5. HARTMANN, H. y KESTER, D. 1983. Plant propagation, principles and practices. 4a ed. New Jersey. Prentice hall. 727 p.

6. HOMMANN, C. 1968. Estudio sobre reproducción y anatomía de hojas y frutos en boldo (Peumus boldus Mol.). Tesis Ing. Forestal. Santiago, Chile. Universidad de Chile, Facultad de Agronomía. 96 p.

7. KANNEGIESSER, U. 1987. Evaluación de biomasa y boldina en boldo (Peumus boldus Mol.), VII Región. Tesis Ing. Forestal. Santiago, Chilc. Universidad de Chile, Facultad de Ciencias Agrarias y Forestales. 97 p.

8. MANCINELLI, P.; ABARZUA, M. y LONGERI, L. 1982. Latencia en (Peumus boldus Mol.), Monimiaceae. Concepción, Chile. Boletín de la Sociedad de Biología de Concepción. 43:63-70.

9. MUÑOZ, M. 1986. Cultivo de embriones y ensayo de germinación en boldo (Peumus boldus Mol.). Tesis Ing. Forestal. Santiago, Chile. Universidad de Chile, Facultad de Ciencias Agrarias y Forestales. $88 \mathrm{p}$.

10. NAVAS, L. 1976. Flora de la cuenca de Santiago de Chile. Santiago, Chile. Ediciones de la Universidad de Chile. v.2 559 p.

11. RODRIGUEZ, R.; MATTHEI, O. y QUEZADA, M. 1983. Flora arbórea de Chile. Concepción, Chile. Ediciones de la Universidad de Concepción. 408 p. 